Int. J. Electrochem. Sci., 11 (2016) $9800-9811$

\title{
Electrochemical Properties of Cellulose Nanofiber/GrapheneNanosheet/Polyaniline Composite Film
}

\author{
Zirun Chen ${ }^{3}$, Chun Wei ${ }^{1,2,3, *}$, Yongyang Gong ${ }^{1,2,3, *}$, Jian $\mathrm{Lv}^{3}$, Rui Du ${ }^{3}$ \\ ${ }^{1}$ Ministry-province jointly-constructed cultivation base for state key laboratory of processing for non- \\ ferrous metal and featured materials, Guangxi Zhuang Autonomous Region \\ ${ }^{2}$ Key Laboratory of New Processing Technology for Nonferrous Metals and Materials, Ministry of \\ Education \\ ${ }^{3}$ College of Materials Science and Engineering, Guilin University of Technology, Guilin 541004, P. R. \\ China \\ *E-mail: 1986024@glut.edu.cn, yygong@glut.edu.cn
}

doi: $10.20964 / 2016.12 .67$

Received: 6 September2016/ Accepted: 12 October 2016 / Published: 10 November 2016

\begin{abstract}
A flexible cellulose nanofibers(CNF)/Graphenenanosheet (GNS)/polyaniline (PANI) composite film was deposited and prepared via vacuum filtration, and then the effect of GNS on the electrochemical properties of the film was studied. Morphology of the CNF/GNS/PANI film was characterized with Fourier transform infrared spectroscopy (FT-IR), Raman spectroscopy (Raman), and field emission scanning electron microscopy (FE-SEM). Moreover, with the increase of GNS content, the electrochemical properties were more evident in the first place but less evident after the GNS content reached $6 \mathrm{wt} \%$. The minimum charge transfer resistance of the composite film was $1.16 \Omega$. The specific capacitance reached $342.87 \mathrm{~F} / \mathrm{g}$ at a current density of $1 \mathrm{~A} / \mathrm{g}$. At $5 \mathrm{~A} / \mathrm{g}, 78.92 \%$ of the capacitance was maintained after 1000 charge-discharge cycles.
\end{abstract}

Keywords:cellulose nanofiber, Graphenenanosheet ,Polyaniline , Flexible , Supercapacitor

\section{$\underline{\text { FULL TEXT }}$}

(C) 2016 The Authors. Published by ESG (www.electrochemsci.org). This article is an open access article distributed under the terms and conditions of the Creative Commons Attribution license (http://creativecommons.org/licenses/by/4.0/). 